\title{
Increased mean platelet volume in patients with panic disorder
}

\author{
This article was published in the following Dove Press journal: \\ Neuropsychiatric Disease and Treatment \\ 13 October 2015 \\ Number of times this article has been viewed
}

\author{
Mehmet Hanifi Kokacya' \\ Umit Sertan Copoglu' \\ Yüksel Kivrak ${ }^{2}$ \\ Mustafa Ari' \\ Musa Sahpolat' \\ Kemal Türker Ulutas ${ }^{3}$ \\ 'Department of Psychiatry, Faculty of \\ Medicine, Mustafa Kemal University, \\ Hatay, ${ }^{2}$ Department of Psychiatry, \\ Faculty of Medicine, Kafkas University, \\ Kars, ${ }^{3}$ Department of Biochemistry, \\ Kadirli State Hospital, Osmaniye, \\ Turkey
}

Objective: The relationship between platelet activation and psychiatric disorders has been shown in previous work. Mean platelet volume (MPV) is a measure of platelet size and a good indicator of platelet activity, which increases in cardiovascular diseases (CVDs). It is known that anxiety is a considerable factor in the etiology of mortality in CVDs. The aim of the present study was to investigate any probable difference in the MPV of patients with panic disorder (PD).

Methods: Sixty-one drug-free patients, aged 18-65 years and diagnosed with PD according to the Diagnostic and Statistical Manual of Mental Disorders, Fourth Edition, were included in the study, along with 63 healthy age- and sex-matched volunteers. The body mass index (BMI) was calculated and MPV measured for each subject.

Results: The MPV was found to be higher in the PD group compared to the control group $(P=0.004)$. There were no significant differences between the two groups in terms of platelet count or BMI.

Conclusion: Alterations in platelet activity may be a reflection of abnormal 5-hydroxytryptamine (5-HT) 1A receptor function in the central nervous system of subjects with a diagnosis of PD. These findings may elucidate the relationship between CVDs and PD. The findings of the present study suggest that MPV is increased in PD patients.

Keywords: mean platelet volume, panic disorder, anxiety

\section{Introduction}

Platelets may reflect biochemical changes in the brain under different psychiatric conditions. ${ }^{1}$ The mean platelet volume (MPV), the measure of platelet size, is considered to be a determinant of platelet function. Increased MPV is thought to be closely associated with cardiovascular diseases (CVDs), mainly acute myocardial infarction (MI) ${ }^{2}$ ischemic heart diseases,${ }^{3}$ and congestive heart failure. ${ }^{4}$ In addition, it has been proposed that for congestive heart failure patients who are admitted into hospital, MPV on admission is an independent predictor of mortality and 6-month mortality. ${ }^{4} \mathrm{MPV}$ has been suggested to be an independent risk factor for atherosclerotic disease. ${ }^{5}$

Peripheral platelet models are widely used as indicators of central serotonin (5-HT) metabolism, as they reflect central serotonergic function. ${ }^{1}$ Serotonin is an important factor in the pathophysiology of anxiety disorders and plays pivotal roles in the vascular system in the regulation of vascular tone and platelet aggregation. ${ }^{6}$ Platelets contain serotonin (5-HT) receptors such as 5-HT 2A, 5-HT 3, and a 5-HT transporter (5-HTT) in their membranes. ${ }^{7,8}$ Experimental studies have shown that 5-HT-potentiated procoagulant responses of platelets enhance thrombogenesis on damaged vascular surfaces. These effects are modulated by selective serotonin reuptake inhibitors (SSRIs), which are commonly used in the treatment of PD. ${ }^{9,10}$ Furthermore, several studies have reported decreased platelet activity after treatment for depression, especially with SSRIs. ${ }^{11,12}$ Several serotonin transporter (5-HTT) abnormalities have been detected in
Kokrespona

Department of Psychiatry, Faculty of Medicine, Mustafa Kemal University, Serinyol Street, PO Box 31100,

Hatay, Turkey

Tel +90 5052585954

Fax +903262295664

Email mhkokacya@mku.edu.tr (c) (i) (5) 2015 Kokacya et al. This work is published by Dove Medical Press Limited, and licensed under Creative Commons Attribution - Non Commercial (unported, v3.0) BY LC License. The full terms of the License are available at http://creativecommons.org/licenses/by-nc/3.0/. Non-commercial uses of the work are permitted without any further permission from Dove Medical Press Limited, provided the work is properly attributed. Permissions beyond the scope of the License are administered by Dove Medical Press Limited. Information on
how to request permission may be found at: http://www.dovepress.com/permissions.php 
panic disorder (PD), although results concerning the synaptic serotonin state are still inconsistent. ${ }^{13,14}$ It has been reported that a hyperserotonergic state resulting from impaired 5-HTT function can cause an anxiety or fear response by stimulating the amygdala. ${ }^{15}$ Conversely, serotonergic agents are known to relieve panic symptoms. ${ }^{16}$

Although a close relationship between ischemic heart disease and anxiety disorders has been proposed, only one study has reported a relationship between MPV and PD in the literature. ${ }^{17}$ In the present study, it was hypothesized that patients with PD have higher MPV levels compared to healthy subjects. The aim of this nonrandomized case-control study was to investigate a possible relationship between MPV levels and PD.

\section{Methods}

\section{Subjects}

Seventy-nine consecutive outpatients, aged 18-65 years, of Research and Training Hospital Outpatient Psychiatry Clinic, School of Medicine, Mustafa Kemal University, had been diagnosed with PD (with or without agoraphobia) according to the fourth edition of Diagnostic and Statistical Manual of Mental Disorders IV-text revision (DSM-IV-TR) over a 6-month period. Of these patients, 61 (32 women and 29 men) patients agreed to participate in the study (Table 1). The control group included 63 physically and mentally healthy age- and sex-matched volunteers (32 men and 31 women). The flowchart of the patient selection process is shown in Figure 1.

Ethical approval for this study was obtained from the local ethics committee in accordance with the Helsinki Declaration. All patients provided written informed consent to participate in this research. Patients were excluded if they were pregnant or breastfeeding or if they had hypertension or metabolic or blood disease, a history of chronic medical drug intake in the previous 2 months, or chronic cardiac and respiratory disease. Patients with any type of comorbid

Table I Characteristics of PD and control groups

\begin{tabular}{llll}
\hline & $\begin{array}{l}\text { PD group } \\
(\mathbf{n}=61)\end{array}$ & $\begin{array}{l}\text { Control group } \\
(\mathbf{n}=63)\end{array}$ & P-value \\
\hline Age & $23.51 \pm 5.37$ & $26.62 \pm 4.23$ & NS \\
MPV (fL) & $10.12 \pm 0.32$ & $8.27 \pm 0.91$ & 0.004 \\
PC $\left(\times 10^{9}\right)$ & $242.65 \pm 34.17$ & $238.84 \pm 36.41$ & NS \\
BMI $\left(\mathrm{kg} / \mathrm{m}^{2}\right)$ & $24.31 \pm 2.19$ & $23.67 \pm 3.43$ & $\mathrm{NS}$ \\
Sex & & & \\
$\quad$ Male & $29(47.55 \%)$ & $31(49.20 \%)$ & $\mathrm{NS}$ \\
Female & $32(52.45 \%)$ & $32(50.80 \%)$ & $\mathrm{NS}$ \\
\hline
\end{tabular}

Abbreviations: BMI, body mass index; fL, femtoliter; MPV, mean platelet volume; NS, no significance; PC, platelet count; PD, panic disorder. psychiatric disorder were excluded. Subjects who had conditions that could affect MPV were also excluded. Body mass index (BMI) was calculated for all subjects.

\section{Blood sampling}

Approximately $10 \mathrm{~mL}$ of blood was obtained from the front of the left arm after a 12-hour fasting period, and the first $2 \mathrm{~mL}$ of blood, which was used for the full blood count, was drawn into a vacutainer tube containing $0.04 \mathrm{~mL}$ of $7.5 \%$ ethylenediaminetetraacetic acid (EDTA, tripotassium salt). The remainder of the blood was drawn into a vacutainer tube without anticoagulant. Total cholesterol, triglyceride, high-density lipoprotein cholesterol, low-density lipoprotein cholesterol, albumin, aspartate transaminase (AST), and alanine transaminase (ALT) were determined using standard methods.

To minimize the potential interference of EDTA in relation to MPV, all blood samples were analyzed 60 minutes after venipuncture. MPV and platelet count were measured using a Cell-Dyn 3500 (Abbott Laboratories, Abbott Park, Chicago, IL, USA) device. After obtaining the blood samples, MPV and platelet counts were measured. Levels of 150,000-400,000 per $\mathrm{mm}^{3}$ of blood were accepted as the normal range for platelet counts and 6.9-11.0 fL (femtoliter, a metric unit of volume equal to $10^{-15} \mathrm{~L}$ ) was used for MPV. All samples were analyzed daily at the Mustafa Kemal University Central Laboratory.

\section{Statistics}

SPSS program v15 (SPSS Inc, Chicago, IL, USA) was used for statistical analysis of data. The Kolmogorov-Smirnov test and the two-tailed independent samples $t$-test were used to compare the groups. Continuous variables are presented as mean \pm standard deviation. A $P$-value $<0.05$ was considered statistically significant.

\section{Results}

The mean age was $23.51 \pm 5.37$ years in the study group and $26.62 \pm 4.23$ years in the control group. There was no difference between the two groups in terms of mean age $(P>0.05)$.

The MPV of the PD group (10.12 $\pm 0.32 \mathrm{fL})$ was significantly higher than that of the control $(8.27 \pm 0.91 \mathrm{fL}$; $P=0.004)$. The mean BMI was $24.31 \pm 2.19 \mathrm{~kg} / \mathrm{m}^{2}$ in the study group and $23.67 \pm 3.43 \mathrm{~kg} / \mathrm{m}^{2}$ in the control group. There was no statistically significant difference between the two groups (Table 1).

There was no significant difference between groups in terms of total cholesterol, triglyceride, AST, ALT, albumin, hemoglobin, or hematocrit ( $P>0.05$; Table 2$)$. 


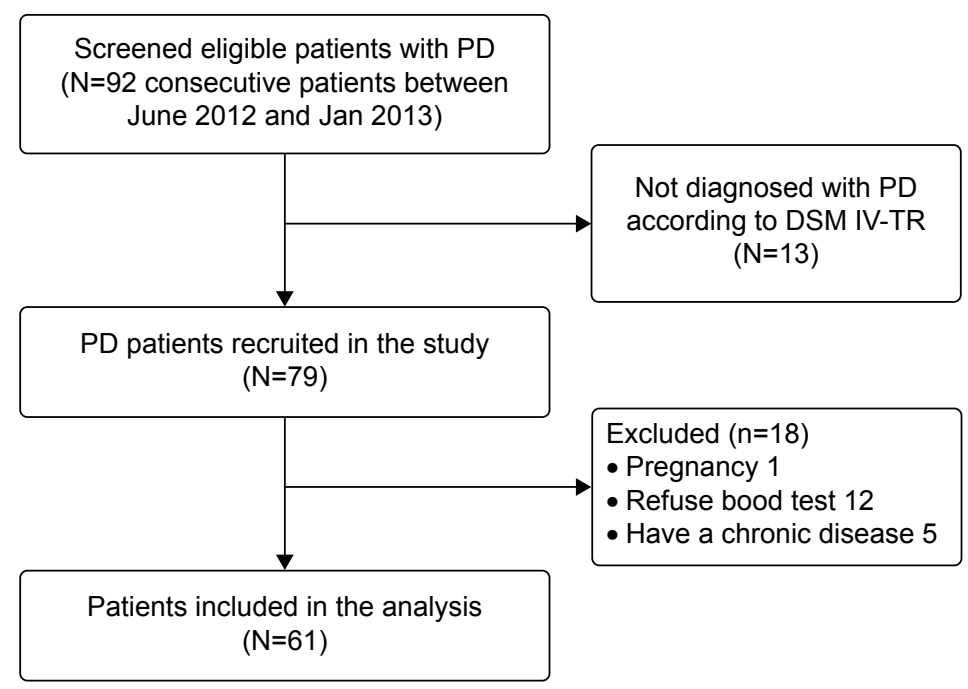

Figure I The flowchart of patient selection process.

Abbreviations: DSM IV-TR, Diagnostic and Statistical Manual of Mental Disorders, Fourth Edition, text revision; PD, panic disorder.

\section{Discussion}

MPV has been defined as a decisive factor in platelet function. It has been shown that platelet size, measured as MPV, correlates with platelets' reactivity. ${ }^{3}$ Previous researchers have claimed that large platelets that include compact granules are more enzymatically and metabolically active than other types. ${ }^{18}$ Depression and anxiety disorders are important factors in the etiology of mortality in CVDs. ${ }^{19}$ Anxiety disorders have been shown to increase the risk of $\mathrm{MI}^{20}$ and $\mathrm{CVD},{ }^{21,22}$ while the risk of cardiac mortality is increased twofold. ${ }^{23}$ Higher anxiety symptom levels have been associated with increased risk for stroke independent of other risk factors. ${ }^{24}$

PD is one of the most frequent anxiety disorders. Some studies have demonstrated links between PD and CVD. ${ }^{25}$ It was shown that patients with PD or phobic anxiety have an increased risk of CVD compared with control subjects. ${ }^{25,26}$

Table 2 Laboratory parameters of PD and control groups

\begin{tabular}{llll}
\hline & $\begin{array}{l}\text { PD group } \\
(\mathbf{n}=6 \mathrm{I})\end{array}$ & $\begin{array}{l}\text { Control } \\
\text { group }(\mathbf{n}=\mathbf{6 3})\end{array}$ & P-value \\
\hline $\begin{array}{l}\text { Triglycerides } \\
\text { (mg/dL) }\end{array}$ & $132.83 \pm 29.23$ & $129.47 \pm 67.63$ & 0.12 \\
AST (U/L) & $23.83 \pm 5.53$ & $23.15 \pm 3.41$ & 0.25 \\
ALT (U/L) & $24.76 \pm 6.26$ & $23.27 \pm 5.33$ & 0.22 \\
Albumin (g/dL) & $4.27 \pm 1.23$ & $4.09 \pm 1.46$ & 0.17 \\
Hb (g/dL) & $15.12 \pm 3.03$ & $15.45 \pm 2.59$ & 0.14 \\
Htc (\%) & $41.46 \pm 5.28$ & $42.55 \pm 5.72$ & 0.08 \\
Total cholesterol & $178.47 \pm 29.22$ & $175.25 \pm 34.17$ & 0.09 \\
(mg/dL) & & & \\
\hline Abbrevati
\end{tabular}

Abbreviations: ALT, alanine aminotransferase; AST, aspartate aminotransferase; $\mathrm{Hb}$, hemoglobin; Htc, hematocrit; PD, panic disorder.
On a pathophysiological level, it has been hypothesized that stress-related conditions may affect several biological mechanisms that negatively influence cardiovascular functions. ${ }^{27}$ It has been suggested that platelet activity is affected by emotional stress and that some coronary events such as MI may be triggered by these stressors. ${ }^{28}$

Quite a few studies have investigated MPV in psychiatric populations. Canan and Ataoglu ${ }^{12}$ reported that MPV was found to be elevated in 15 patients with major depression. After 8 weeks of escitalopram treatment, it was shown that MPV levels were statistically significantly lower than baseline in 15 patients with major depression. ${ }^{12}$ In a large population-based study, 289 patients with major depression were found to have increased MPV levels in comparison with control subjects. ${ }^{5}$

In the present study, we found increased MPV levels in patients with PD. Although a relationship between increased platelet activity and anxiety, depression, and post-MI depression has been reported on earlier, the relationship between anxiety and platelet functions has not been precisely proven. ${ }^{29}$ In a recent study, it was reported that patients with anxiety disorder showed multiple changes in platelet parameters. ${ }^{30}$ These changes originated from a decrease of the serotonin transporter in $[3 \mathrm{H}]$ imipramine-binding sites of platelets and an increase in 5-HT 2A receptor-binding sites on the surface of platelets. ${ }^{31}$ Abnormalities in 5-HT $1 \mathrm{~A}$ receptor functions and alterations in 5-HTT levels and activity are described in platelets from patients affected by anxiety disorders. ${ }^{32,33}$ Moreover, several reports have pointed toward decreased platelet activity after treatment with SSRIs 
in patients with major depression. ${ }^{11,34}$ It has been suggested that some mechanisms that lead to platelet abnormalities in major depression are altered intraplatelet concentrations of monoamines and catecholamines, altered platelet function by increased plasma concentrations of 5-HT and epinephrine, and altered platelet function by increased intraplatelet calcium mobilization. ${ }^{35}$

It is known that patients with anxiety, depression, or disruptive behavior disorder have increased catecholamine levels, sympathetic activity, and cortisol secretion. ${ }^{36}$ Vizioli et $\mathrm{al}^{37}$ have shown that increased sympathetic activity can also cause higher MPV values. On the basis of these reports, some investigators have postulated that the sympathoadrenal activation may stimulate platelets via 2-adrenoreceptor activation, ${ }^{38}$ which in turn induces shape change and thereby increases MPV. ${ }^{39}$ Anxiety and depressive disorders are also associated with increased inflammatory cytokine levels, endothelial dysfunction, and platelet reactivation. As in the central nervous system, plasma platelets play a role in serotonin synthesis, secretion, and reuptake. ${ }^{40}$

Serotonin not only has a pivotal role in the pathophysiology of depression and PD, but also participates in hemostasis by affecting platelet aggregation. ${ }^{6}$ Serotonin 5-HT2A receptors and serotonin transporter receptors in platelets and the brain are encoded by the same gene. ${ }^{40}$ It has been reported that patients with anxiety disorder have increased platelet reactivation related to serotonin..$^{40}$ Dysregulation of serotonin and increased adrenaline, which are crucial in the etiology of PD, induce platelet activation. ${ }^{30}$ In one study, platelet 5-HT uptake maximal velocity $(V \max )$ and its associated affinity constant $\left(K_{\mathrm{m}}\right)$ were found to be lower in PD patients than in normal control subjects. ${ }^{41}$ In this study, Kang et al reported that patients with PD showed abnormalities in platelet 5-HTT function; furthermore, they found that after 12 weeks of paroxetine treatment, the $K_{\mathrm{m}}$ values of platelet serotonin transporters increased in parallel to clinical improvement. They speculated that impaired 5-HTT function might be related to the dysregulation of the autonomic nervous system in PD. ${ }^{41}$

In the literature, this is the second study to evaluate MPV levels in PD patients. Gul et a ${ }^{17}$ investigated the correlation of levels of MPV in 37 PD patients; contrary to our findings, they found lower MPV levels in PD patients compared to the control group. They speculated that abnormal 5-HT metabolism, such as specific alterations of the 5-HT receptor functional state in platelets of PD patients, could lead to decreased MPV. ${ }^{17}$ But they could not explain the exact mechanism of or reason for the decreased MPV in PD patients. Moreover, their sample size was small $(n=37)$, so it cannot be generalized to all PD patients.

As PD and depression share common pathophysiological mechanisms, they both are treated with similar drugs (SSRIs). Because a vast number of studies have reported increased MPV in patients with major depression, we believe that increased MPV levels can be expected in PD patients.

This study has some limitations. First, the sample size is relatively small, and to generalize these results, multicenter studies with more patients with PD are needed. Second, the study population was not screened for other conditions that have been reported to affect platelet activity, such as cigarette smoking and hypertension. Third, as panic attack severity is not measured by scales, the correlation between MPV and panic severity could not be evaluated.

\section{Conclusion}

In our study, MPV levels of patients with PD were higher than those of control subjects. These findings may elucidate the relationship between CVDs and PD. The findings of the present study suggest that MPV is increased in PD patients. Better-designed and more advanced studies are necessary to determine the exact function of platelets and the importance of MPV in PD patients.

\section{Disclosure}

The authors report no conflicts of interest in this work.

\section{References}

1. Camacho A, Dimsdale JE. Platelets and psychiatry: lessons learned from old and new studies. Psychosom Med. 2000;62(3):326-336.

2. Huczek Z, Kochman J, Filipiak KJ, et al. Mean platelet volume on admission predicts impaired reperfusion and long-term mortality in acute myocardial infarction treated with primary percutaneous coronary intervention. J Am Coll Cardiol. 2005;46(2):284-290.

3. Slavka G, Perkmann T, Haslacher H, et al. Mean platelet volume may represent a predictive parameter for overall vascular mortality and ischemic heart disease. Arterioscler Thromb Vasc Biol. 2011;31(5): $1215-1218$.

4. Kandis H, Ozhan H, Ordu S, et al. The prognostic value of mean platelet volume in decompensated heart failure. Emerg Med J. 2011;28(7): 575-578.

5. Canan F, Dikici S, Kutlucan A, et al. Association of mean platelet volume with DSM-IV major depression in a large community-based population: the MELEN study. J Psychiatr Res. 2012;46(3):298-302.

6. Vanhoutte PM. Platelet-derived serotonin, the endothelium, and cardiovascular disease. J Cardiovasc Pharmacol. 1991;17:S13.

7. Purselle DC, Nemeroff CB. Serotonin transporter: a potential substrate in the biology of suicide. Neuropsychopharmacology. 2003; 28(4):613-619.

8. Stratz C, Trenk D, Bhatia HS, Valina C, Neumann F-J, Fiebich BL. Identification of 5-HT3 receptors on human platelets: increased surface immunoreactivity after activation with adenosine diphosphate (ADP) and thrombin receptor-activating peptide (TRAP). Thromb Haemost. 2008;99(4): 784-786. 
9. Lopez-Vilchez I, Diaz-Ricart M, White JG, Escolar G, Galan AM. Serotonin enhances platelet procoagulant properties and their activation induced during platelet tissue factor uptake. Cardiovasc Res. 2009;84(2):309-316.

10. Galan AM, Lopez-Vilchez I, Diaz-Ricart M, et al. Serotonergic mechanisms enhance platelet-mediated thrombogenicity. Thromb Haemost. 2009;102(3):511-519.

11. Markovitz JH, Shuster JL, Chitwood WS, May RS, Tolbert LC. Platelet activation in depression and effects of sertraline treatment: an open-label study. Am J Psychiatry. 2000;157(6):1006-1008.

12. Ataoglu A, Canan F. Mean platelet volume in patients with major depression: effect of escitalopram treatment. J Clin Psychopharmacol. 2009;29(4):368-371.

13. Kang E-H, Shim H-B, Kim K-J, Park J-E, Lee I-S, Yu B-H. Platelet serotonin transporter function after short-term paroxetine treatment in patients with panic disorder. Psychiatry Res. 2010;176(2):250-253.

14. Iny LJ, Pecknold J, Suranyi-Cadotte BE, et al. Studies of a neurochemical link between depression, anxiety, and stress from $[3 \mathrm{H}]$ imipramine and $[3 \mathrm{H}]$ paroxetine binding on human platelets. Biol Psychiatry. 1994;36(5):251-291.

15. Lesch K-P, Bengel D, Heils A, et al. Association of anxiety-related traits with a polymorphism in the serotonin transporter gene regulatory region. Science. 1996;274(5292):1527-1531.

16. Ballenger JC. Remission rates in patients with anxiety disorders treated with paroxetine. J Clin Psychiatry. 2004;65(12):1696-1707.

17. Gül IG, Eryılmaz G, Özten E, Sayar GH. Decreased mean platelet volume in panic disorder. Neuropsychiatr Dis Treat. 2014;10:1665.

18. Martin J, Shaw T, Heggie J, Penington D. Measurement of the density of human platelets and its relationship to volume. Br J Haematol. 1983;54(3):337-352.

19. Glassman AH, Shapiro PA. Depression and the course of coronary artery disease. Am J Psychiatry. 1998;155(1):4-11.

20. Scherrer JF, Chrusciel T, Zeringue A, et al. Anxiety disorders increase risk for incident myocardial infarction in depressed and nondepressed veterans administration patients. Am Heart J. 2010;159(5):772-779.

21. Härter MC, Conway KP, Merikangas KR. Associations between anxiety disorders and physical illness. Eur Arch Psychiatry Clin Neurosci. 2003;253(6):313-320.

22. Vogelzangs N, Seldenrijk A, Beekman AT, van Hout HP, de Jonge P, Penninx BW. Cardiovascular disease in persons with depressive and anxiety disorders. J Affect Disord. 2010;125(1):241-248.

23. Roest AM, Martens EJ, de Jonge P, Denollet J. Anxiety and risk of incident coronary heart disease: a meta-analysis. J Am Coll Cardiol. 2010;56(1): $38-46$.

24. Lambiase MJ, Kubzansky LD, Thurston RC. Prospective study of anxiety and incident stroke. Stroke. 2014;45(2):438-443.

25. Weissman MM, Markowitz JS, Ouellette R, Greenwald S, Kahn JP. Panic disorder and cardiovascular/cerebrovascular problems: results from a community survey. Am J Psychiatry. 1990;147(11):1504.
26. Kawachi I, Colditz GA, Ascherio A, et al. Prospective study of phobic anxiety and risk of coronary heart disease in men. Circulation. 1994;89(5): 1992-1997.

27. Everson-Rose SA, Lewis TT. Psychosocial factors and cardiovascular diseases. Annu Rev Public Health. 2005;26:469-500.

28. Markovitz JH, Matthews KA. Platelets and coronary heart disease: potential psychophysiologic mechanisms. Psychosom Med. 1991;53(6):643-668.

29. Schins A, Hamulyák K, Scharpé S, et al. Whole blood serotonin and platelet activation in depressed post-myocardial infarction patients. Life Sci. 2004;76(6):637-650.

30. Aschbacher K, Mills PJ, von Känel R, et al. Effects of depressive and anxious symptoms on norepinephrine and platelet $\mathrm{P}$-selectin responses to acute psychological stress among elderly caregivers. Brain Behav Immun. 2008;22(4):493-502.

31. Greisenegger S, Endler G, Hsieh K, Tentschert S, Mannhalter C, Lalouschek W. Is elevated mean platelet volume associated with a worse outcome in patients with acute ischemic cerebrovascular events? Stroke. 2004;35(7):1688-1691.

32. Marazziti D, Rossi A, Dell'Osso L, et al. Decreased platelet 3 H-paroxetine binding in untreated panic disorder patients. Life Sci. 1999;65(25): 2735-2741.

33. Lesch KP, Wolozin BL, Murphy DL, Riederer P. Primary structure of the human platelet serotonin uptake site: identity with the brain serotonin transporter. J Neurochem. 1993;60(6):2319-2322.

34. Serebruany VL, Gurbel PA, O'Connor CM. Platelet inhibition by sertraline and $\mathrm{N}$-desmethylsertraline: a possible missing link between depression, coronary events, and mortality benefits of selective serotonin reuptake inhibitors. Pharmacol Res. 2001;43(5):453-462.

35. Nemeroff CB, Musselman DL. Are platelets the link between depression and ischemic heart disease? Am Heart J. 2000;140(4):S57-S62.

36. Strike PC, Steptoe A. Psychosocial factors in the development of coronary artery disease. Prog Cardiovasc Dis. 2004;46(4):337-347.

37. Vizioli L, Muscari S, Muscari A. The relationship of mean platelet volume with the risk and prognosis of cardiovascular diseases. Int $J$ Clin Pract. 2009;63(10):1509-1515.

38. Hjemdahl P, Larsson P, Wallen N. Effects of stress and beta-blockade on platelet function. Circulation. 1991;84(6 suppl):VI44-VI61.

39. Thompson CB, Jakubowski JA. The pathophysiology and clinical relevance of platelet heterogeneity. Blood. 1988;72(1):1-8.

40. Parakh K, Sakhuja A, Bhat U, Ziegelstein RC. Platelet function in patients with depression. South Med J. 2008;101(6):612-617.

41. Kang E-H, Lee I-S, Park J-E, Kim K-J, Yu B-H. Platelet serotonin transporter function and heart rate variability in patients with panic disorder. J Korean Med Sci. 2010;25(4):613-618.
Neuropsychiatric Disease and Treatment

\section{Publish your work in this journal}

Neuropsychiatric Disease and Treatment is an international, peerreviewed journal of clinical therapeutics and pharmacology focusing on concise rapid reporting of clinical or pre-clinical studies on a range of neuropsychiatric and neurological disorders. This journa is indexed on PubMed Central, the 'PsycINFO' database and CAS,

\section{Dovepress}

and is the official journal of The International Neuropsychiatric Association (INA). The manuscript management system is completely online and includes a very quick and fair peer-review system, which is all easy to use. Visit http://www.dovepress.com/testimonials.php to read real quotes from published authors. 